\title{
STRATEGI PENGEMBANGAN PALA (Myristica fragan haitt) DI KECAMATAN TANJUNG RAYA KABUPATEN AGAM (Studi kasus : Kelompok Tani Sabik Tajam Nagari Tanjung Sani)
}

\author{
Development Strategy Of Nutmeg in Tanjung Raya Sub-District, Agam \\ District (Case Study: Sabik Tajam Farmers Group, Nagari Tanjung Sani)
}

\author{
Devi Analia \\ Fakultas Pertanian Universitas Andalas Padang \\ analia_devi@yahoo.com
}

\begin{abstract}
The study aims to analyze development strategy of nutmeg (Myristic fragan haitt) in Tanjung Raya Sub-district, Agam District. The study applied decriptive method. The data were collected through in depth interview with three internal key infromants, in this case farmers, and external key informants including head of forestry and plantation department of Agam District, and one nutmeg farmer. SWOT analysis were applied to formulate development strategy of nutmeg at Sabik Tajam farmers group in Tanjung Raya Sub-district, Agam District. The development strategies include developing cooperation with government and private sector; technology improvement for value added of nutmeg farmers income through nutmeg agro-industry; promotion of nutmeg sector by the government, both in local and international market; participating in training held by relevant government authorities particularly those related to nutmeg processing and establishing house of HPT (plant pests and disease) to overcome the pests and disease; conducting training to the farmers covering the marketing aspect; cultivation and technology development; the involvement of UPTD (technical implementation unit at local) in cultivation and HPT of nutmeg; optimizing the resources and marketing, and develop cooperation with the farmers group that have more advanced technology.
\end{abstract}

Keywords : nutmeg, IFE matrix, EFE, SWOT, nutmeg development strategy

\section{PENDAHULUAN}

Pembangunan Pertanian di Indonesia tetap dianggap terpenting dari keseluruhan pembangunan ekonomi, apalagi semenjak sektor pertanian ini menjadi penyelamat perekonomian nasional karena justru pertumbuhannya meningkat, sementara sektor lain pertumbuhannya negatif. Beberapa alasan yang mendasari pentingnya pertanian di Indonesia : (1) potensi sumberdaya yang besar dan beragam, (2) pangsa terhadap pendapatan nasional cukup be- 
sar, (3) besarnya penduduk yang menggantungkan hidupnya pada sektor ini dan (4) menjadi basis pertumbuhan di pedesaan (Asmara, 2004).

Salah satu sektor pertanian yang memiliki potensi adalah sektor perkebunan. Indonesia kaya akan tanaman perkebunan yang bernilai tinggi dan mampu bersaing di pasar dunia. Rempah-rempah merupakan salah satu jenis tanaman perkebunan yang potensial untuk diperdagangkan. Indonesia cukup diperhitungkan di dunia internasional karena merupakan salah satu negara penghasil rempah-rempah. Salah satu rempah-rempah yang asli berasal dari Indonesia adalah pala.

Tanaman pala (Myristica fragran haitt) dikenal dengan tanaman rempah yang memiliki nilai ekonomis merupakan tanaman asli Indonesia yang berasal dari kepulauan Banda dan Maluku. Hasil tanaman pala yang biasa dimanfaatkan adalah buah pala. Bagian buah yang bernilai ekonomi cukup tinggi adalah biji pala dan fuli (bunga) yang dapat dijadikan minyak pala. Sedangkan daging buah pala dapat dimanfaatkan untuk diolah menjadi manisan pala, asinan pala, dodol pala, selai pala dan sirup pala (Larasati, dkk. 2008).

Hampir 100\% pengusahaan tanaman pala adalah Perkebunan Rakyat (PR), sehingga Pengembangannya akan berdampak langsung pada kesejahteraan petani (BPS Indonesia, 2009). Peningkatan kesejahteraan petani dapat dicapai melalui upaya peningkatan produksi, produktivitas dan pendapatan usahatani (Simatupang, 2005).

Pala adalah salah satu tanaman perkebunan rakyat yang menjadi sumber pendapatan bagi sebagian masyarakat di Propinsi Sumatera Barat. Kabupaten Agam merupakan penghasil pala terbesar di Sumatera Barat. Berdasarkan data Dinas Perkebunan Propinsi Sumatera Barat (2009), Kabupaten Agam memiliki areal tanaman pala seluas 935 Ha. Pala yang ditanamam oleh masyarakat merupakan perkebunan rakyat.

Salah satu kecamatan yang menjadi sentra produksi pala di Kabupaten Agam adalah Kecamatan Tanjung Raya dan tanaman yang paling tinggi produksinya. Menurut Camat Tanjung Raya Syatria, Kecamatan Tanjung Raya merupakan daerah berpotensi sebagai pengembangan pohon pala sesuai dengan kemiringan tanah pada beberapa tempat perbukitan yang dimiliki dapat mendukung tanaman pala tersebut. Dinas Kehutanan dan Perkebunan Kabupaten Agam terus mensosialisasikan tentang optimalisasi pemanfaatan lahan didaerah yang belum diusahakan Pemerintah Kecamatan Tanjung Raya sebanyak $935 \mathrm{Ha}$.

Kecamatan Tanjung Raya Kabupaten Agam Sumatera Barat adalah daerah yang terdapat disekitaran danau maninjau. Sabagai daerah disekitaran danau maka banyak masyarakat yang bekerja dalam bidang pertanian. Pada Kecamatan Tanjung Raya ini berdasarkan potensi lahan yang ada maka petani banyak bekerja di lahan sawah irigasi dan kebun/tegalan. Selain dari yang di- 
usahakan itu masih terdapat lahan hutan yang sebenarnya sangat dibutuhkan untuk mendukung daerah serapan lahan disekitaran danau.

Selama ini terdapat pertentangan kepentingan antara petani yang ingin mengusahakan pertaniannya secara intensif dengan ketetapan harus mempertahankan keasrian hutan. Petani disatu sisi adalah pihak yang biasanya kekurangan modal, tidak memiliki bargaining position yang kuat dan cendrung berusahatani berdasarkan keinginan saja dan tanpa memperhatikan kontur lahan. Akibatnya bila hal ini terus berlanjut maka akan merusak lahan di sekitaran danau maninjau. Di sisi lain pemerintah bertanggung jawab untuk memelihara ekosistem sekitaran danau sehingga keasriannya terus berlanjut. Salah satu yang dapat dilaksanakan oleh pemerintah adalah reboisasi yaitu dengan menanam pohon pada kawasan hutan yang rusak baik oleh karena ulah manusia ataupun karena bencana alam seperti longsor dan gempa.

Dari dua kontradikasi yang ada maka timbul permasalahan antara pemerintah dan petani disekitaran danau. Tapi tentu tidak bijaksana apabila kemudian pemerintah melarang petani mengelola lahan yang dimilikinya secara turun temurun tanpa memberikan solusi yang dapat memberikan keuntungan bagi petani sehingga dapat membiayai keluarganya dan meningkatkan taraf pendapatannya.

Tanaman pala dipilih karena beberapa alasan yaitu yang pertama sebagai salah satu tanaman rempah asli Indonesia yang berasal dari Banda dan Maluku tanaman pala sudah menyebar seluruh Indonesia. Tanaman ini berupa pohon tinggi yang cocok ditanam sebagai tanaman hutan. Tanaman ini dapat beradaptasi pada daerah sampai pada ketinggian $700 \mathrm{~m}$ diatas permuakaan laut dan daerah lereng. Selain itu Tanaman pala dipilih karena tanaman ini memiliki nilai ekonomis yang tinggi. Dikatakan ekonomis karena harga tanaman pala ini cukup tinggi. Harga tersebut didukung oleh penelitian yang dilakukan oleh Reny Hidayati (2011) dimana pendapatan dari pala kering adalah sebesar Rp 5.919.500,91/100 kg dan Rp 4.761.336,96/400 kg untuk pala kering.

Oleh karena itu permasalahan yang ingin dipecahkan dalam penelitian ini adalah merumuskan strategi pengembangan pala (Myristica fragan haitt ) Di Kecamatan Tanjung Raya Kabupaten Agam (Studi kasus : Kelompok Tani Sabik Tajam Nagari Tanjung Sani). Berdasarkan hal tersebut, maka penulis merasa perlu melakukan penelitian dengan judul "Strategi Pengembangan Agribisnis Pala (Myristica fragan haitt) Perkebunan Rakyat di Kabupaten Agam" dengan tujuan penelitian adalah merumuskan Strategi Pengembangan Pala (Myristic fragan haitt) di Kecamatan Tanjung Raya Kabupaten Agam (Studi kasus : Kelompok Tani Sabik Tajam Nagari Tanjung Sani)". 


\section{Tempat dan Waktu Penelitian}

\section{METODE PENELITIAN}

Penelitian ini dilaksanakan di Kelompok Tani Sabik Tajam Nagari Tanung Sani Kecamatan Tanjung Raya Kabupaten Agam. Pemilihan lokasi dilakukan secara purposive dengan pertimbangan Kelompok Sabik Tajam merupakan kelompok tani dengan luas penanaman pala yang besar yaitu 25 Ha dibandingkan dengan kelompok tani lainnya dan didukung juga dengan Kecamatan Tanjung Raya merupakan salah satu sentra penghasil pala terluas di Kabupaten Agam.

\section{Metode Penelitian}

Metode yang digunakan dalam penelitian ini adalah metode deskriptif. Metode deskriptif adalah suatu metode dalam meneliti status sekelompok manusia, suatu objek, suatu set kondisi, suatu sistim pemikiran ataupun suatu kelas peristiwa pada masa sekarang. Metode deskriptif yang dipakai yaitu penelitian studi kasus (case studi).

\section{Metode Pengumpulan Data}

Data yang diambil dalam penelitian ini yaitu data primer dan data sekunder. Data primer diperoleh melalui studi lapangan yaitu melakukan wawancara langsung dengan menggunakan kuisioner atau daftar pertanyaan yang telah disediakan kepada responden, dan data sekunder diperoleh dari literatur terkait dan studi kepustakaan.

Responden yang diambil terdiri dari dua kelompok sampel, yaitu ;

1. Internal, yaitu : 3 orang Petani Pala (1 orang ketua kelompok tani dan 2 orang anngota kelompok tani.

2. Eksternal, yaitu :

a. Kepala Dinas Perkebunan dan Kehutanan Kabupaten Agam (1 Orang)

b. Pedagang pala yang berhubungan dengan petani pala di Kecamatan Tanjung Raya Kabupaten Agam (1 Orang)

\section{Sumber Data dan Teknik Pengumpulan Data}

Untuk Tujuan penelitian ini yaitu menetapkan strategi yang tepat untuk pengembangan pala di Kecamatan Tanjung Raya Kabupaten Agam, data yang dikumpulkan dibagi menjadi dua yaitu faktor internal dan eksternal yang mempengaruhi pengembangan agribisnis pala di Kecamatan Tanjung Raya Kabupaten Agam. Data diperoleh melalui wawancara yang mendalam dengan informan kunci berupa kekuatan, kelemahan, tantangan dan ancaman yang dimiliki. 


\section{Variabel Yang diamati}

Untuk merumuskan strategi pengembangan agribisnis pala maka variabel yang diamati adalah Mengidentifikasi faktor internal yaitu hal-hal yang dapat dikendalikan petani pala yang terdiri dari kekuatan dan kelemahan. Mengidentifikasi faktor eksternal yaitu hal-hal yang tidak dapat dikendalikan oleh petani pala yang terdiri dari peluang dan ancaman.

\section{Analisis Data}

Untuk menganalisa data yang diperoleh digunakan beberapa metoda analisa sesuai dengan tujuan yang ingin dicapai, untuk lebih jelasnya metoda analisa tersebut adalah sebagai berikut: Untuk Tujuan penelitian yaitu menetapkan strategi yang tepat untuk pengembangan agribisnis pala di Kecamatan Tanjung Raya Kabupaten Agam, data yang dikumpulkan dibagi menjadi dua yaitu tahap pertama menggunakan matriks IFE dan EFE dan tahap kedua menggunakan matriks SWOT serta tahapan akhir decision stage.

\section{HASIL DAN PEMBAHASAN}

\section{Perumusan Strategi Pengembangan Pala di Kecamatan Tanjung Raya Matriks IFE}

Nilai IFE yang didapatkan sebesar 2,709 yang artinya Perkebunan pala di Nilai IFE yang didapatkan sebesar 2,709 yang artinya Perkebunan pala di Tanung Sani memiliki posisi internal yang kuat karena mampu menggunakan kekuatan yang ada untuk mengurangi kelemahan yang dimiliki. Faktor dengan bobot tertinggi dan peringkat tertinggi merupakan faktor yang sangat mempengaruhi perkebunan pala di Tanjung Sani.

\section{Matriks IFE}

\begin{tabular}{|c|c|c|c|}
\hline \multirow{2}{*}{$\begin{array}{l}\text { Faktor -Faktor Internal } \\
\text { Kekuatan }\end{array}$} & \multicolumn{2}{|c|}{ Rata-rata } & \multirow{2}{*}{$\begin{array}{l}\text { Nilai } \\
\text { Tertimbang }\end{array}$} \\
\hline & Bobot & Peringkat & \\
\hline $\begin{array}{l}\text { Kadar minyak pala di Nagari Tanjung Sani } \\
\text { lebih unggul dibandingkan dengan daerah } \\
\text { lainnya }\end{array}$ & 0,070 & 4 & 0,28 \\
\hline $\begin{array}{l}\text { Kondisi tanah yang subur hasil letusan } \\
\text { gunung } \\
\text { pertumbuhan pala }\end{array}$ & 0,063 & 4 & 0,252 \\
\hline $\begin{array}{l}\text { Visi dan Misi Kecamatan Tanung Raya } \\
\text { Kabupaten Agam yang mendukung } \\
\text { pengembangan pala }\end{array}$ & 0,070 & 4 & 0,28 \\
\hline $\begin{array}{l}\text { Musim panen pala yang terus berbuah } \\
\text { sepanjang masa }\end{array}$ & 0,056 & 3 & 0,168 \\
\hline $\begin{array}{l}\text { Tanjung Raya merupakan salah satu } \\
\text { wilayah terbesar dalam memproduksi pala }\end{array}$ & 0,070 & 4 & 0,28 \\
\hline Tenaga kerja yang mendukung dan & 0,056 & 3 & 0,168 \\
\hline
\end{tabular}


berpengalaman dalam hal budidaya

Pala dijual kepada pedagang pengumpul 0,056

"Toke" langganan

$\begin{array}{lllll}\text { Budidaya yang dilakukan secara turun } 0,063 & 3 & 0,189\end{array}$ temurun sehingga membuat petani memiliki pengalaman yang cukup lama

\begin{tabular}{|c|c|c|c|}
\hline Kelemahan & & & \\
\hline $\begin{array}{l}\text { Belum ada pelatihan yang diadakan untuk } \\
\text { menanggulangi serangan hama penyakit }\end{array}$ & 0,056 & 2 & 0,112 \\
\hline $\begin{array}{l}\text { Bibit yang digunakan berasal dari pohon } \\
\text { induk belum cukup umur (Prenursery) }\end{array}$ & 0,063 & 2 & 0,126 \\
\hline $\begin{array}{l}\text { Petani kurang aktif dalam menerima } \\
\text { informasi baru }\end{array}$ & 0,070 & 2 & 0,14 \\
\hline $\begin{array}{l}\text { Peran kelompok tani yang ada belum } \\
\text { sepenuhnya berfungsi }\end{array}$ & 0,056 & 2 & 0,112 \\
\hline $\begin{array}{l}\text { Teknologi yang digunakan oleh petani } \\
\text { masih tradisonal }\end{array}$ & 0,063 & 2 & 0,126 \\
\hline $\begin{array}{l}\text { Pengolahan hasil pala yang belum optimal } \\
\text { hanya dijual dalam bentuk biji kering }\end{array}$ & 0,056 & 1 & 0,056 \\
\hline Minat petani untuk pengolahan pala kurang & 0,063 & 2 & 0,126 \\
\hline $\begin{array}{l}\text { Bahan baku untuk pengolahan minyak atsiri } \\
\text { yang tidak terpenuhi }\end{array}$ & 0,063 & 2 & 0,126 \\
\hline Total & \multicolumn{2}{|c|}{1} & 2,709 \\
\hline
\end{tabular}

Kekuatan utama bagi adalah variabel kekuatan yang memiliki nilai peringkat 4 yaitu kadar minyak pala di Nagari Tanjung Sani lebih unggul dibandingkan dengan daerah lainnya, kondisi tanah yang subur hasil letusan gunung sehingga mendukung pertumbuhan pala, visi dan misi Kabupaten Agam yang mendukung pengembangan pala, dan Tanjung Raya merupakan salah satu wilayah terbesar dalam memproduksi pala. Kelemahan utama adalah variabel kelemahan yang memiliki nilai peringkat 1 yaitu Pengolahan hasil pala yang belum optimal hanya dijual dalam bentuk biji kering. Nilai EFE yang didapat sebesar 3,312 yang artinya perkebunan pala di Tanjung Sani mampu menarik keuntungan dari peluang eksternal dan menghindari ancaman yang datang. Faktor yang memiliki nilai bobot tertinggi dan peringkat yang lebih tinggi menandakan bahwa faktor tersebut merupakan faktor penting dan mendapat respon yang sangat baik. Peluang utama adalah memiliki nilai 4, yaitu peningkatan permintaan pasar pelanggan tinggi, faktor iklim dan cuaca yang mendukung, prospek pala yang menjanjikan, bibit yang diberikan oleh Pemerintah merupakan bibit seleksi, pala bisa diolah menjadi berbagai macam agroindustri. Ancaman utama adalah memiliki nilai 4 yaitu UPTD lebih memilih tanaman pangan. 


\section{Strategi SO}

Strategi ini menggunakan atau mengoptimalkan kekuatan internal untuk memanfaatkan peluang eksternal. Strategi SO yang dapat dihasilkan adalah: swasta

Membangun hubungan kerjasama dengan pihak pemerintah dan

Hubungan kerjasama dapat terjalin antara pihak pemerintah dan swasta dengan kelompok tani di Tanjung Sani. Peningkatan perbaikan teknologi nilai tambah dan pendapatan petani, melalui pasca panen pengolahan biji dan fuli menjadi minyak atsiri dan pengolahan daging buah pala menjadi makanan ringan, dan aneka produk-produk lain yang bernilai ekonomis tinggi

Pemerintah dengan pihak yang terkait melakukan promosi komoditas pala baik di dalam maupun luar negeri. Hal ini bertujuan agar produk pala memiliki daya saing yang kuat di pasar internasional.

\section{Strategi WO}

Strategi ini memperbaiki atau mengatasi kelemahan internal usaha untuk memanfaatkan peluang ekternal. Strategi WO yang dihasilkan adalah:

Mengikuti pelatihan yang diadakan oleh pihak pemerintah terkait pengolahan hasil produk pala. Pemerintah dapat membuat pelatihan pengolahan pala dalam bentuk Agroindustri sehingga dapat menambah nilai tambah pada produk pala.

Membentuk rumah HPT untuk dapat mengatasi hama dan penyakit yang menyerang

Hama dan penyakit yang menyerang pala dapat membuat kerugian pada petani pala.

\section{Matriks EFE}

\begin{tabular}{|c|c|c|c|}
\hline \multirow{2}{*}{$\begin{array}{l}\text { Faktor-Faktor Eksternal } \\
\text { Peluang }\end{array}$} & \multicolumn{2}{|c|}{ Rata-rata } & \multirow{2}{*}{$\begin{array}{l}\text { Nilai } \\
\text { Tertimbang }\end{array}$} \\
\hline & Bobot & $\begin{array}{l}\text { Peringka } \\
t\end{array}$ & \\
\hline $\begin{array}{l}\text { Peningkatan permintaan pasar pelanggan } \\
\text { tinggi }\end{array}$ & 0,058 & 4 & 0,232 \\
\hline Faktor iklim dan cuaca yang mendukung & 0,064 & 4 & 0,256 \\
\hline $\begin{array}{l}\text { CSR dengan PLN dan Pemda dalam hal } \\
\text { bantuan bibit }\end{array}$ & 0,051 & 2 & 0,102 \\
\hline Peluang ekspor pala yang besar & 0,058 & 3 & 0,174 \\
\hline $\begin{array}{l}\text { Sumatera Barat sebagai salah satu daerah } \\
\text { utama penghasil pala di Indonesia khusus } \\
\text { Tanjung Raya }\end{array}$ & 0,051 & 3 & 0,153 \\
\hline Prospek pala yang menjanjikan & 0,064 & 4 & 0,256 \\
\hline Pala merupakan salah satu bahan baku & 0,051 & 3 & 0,153 \\
\hline
\end{tabular}




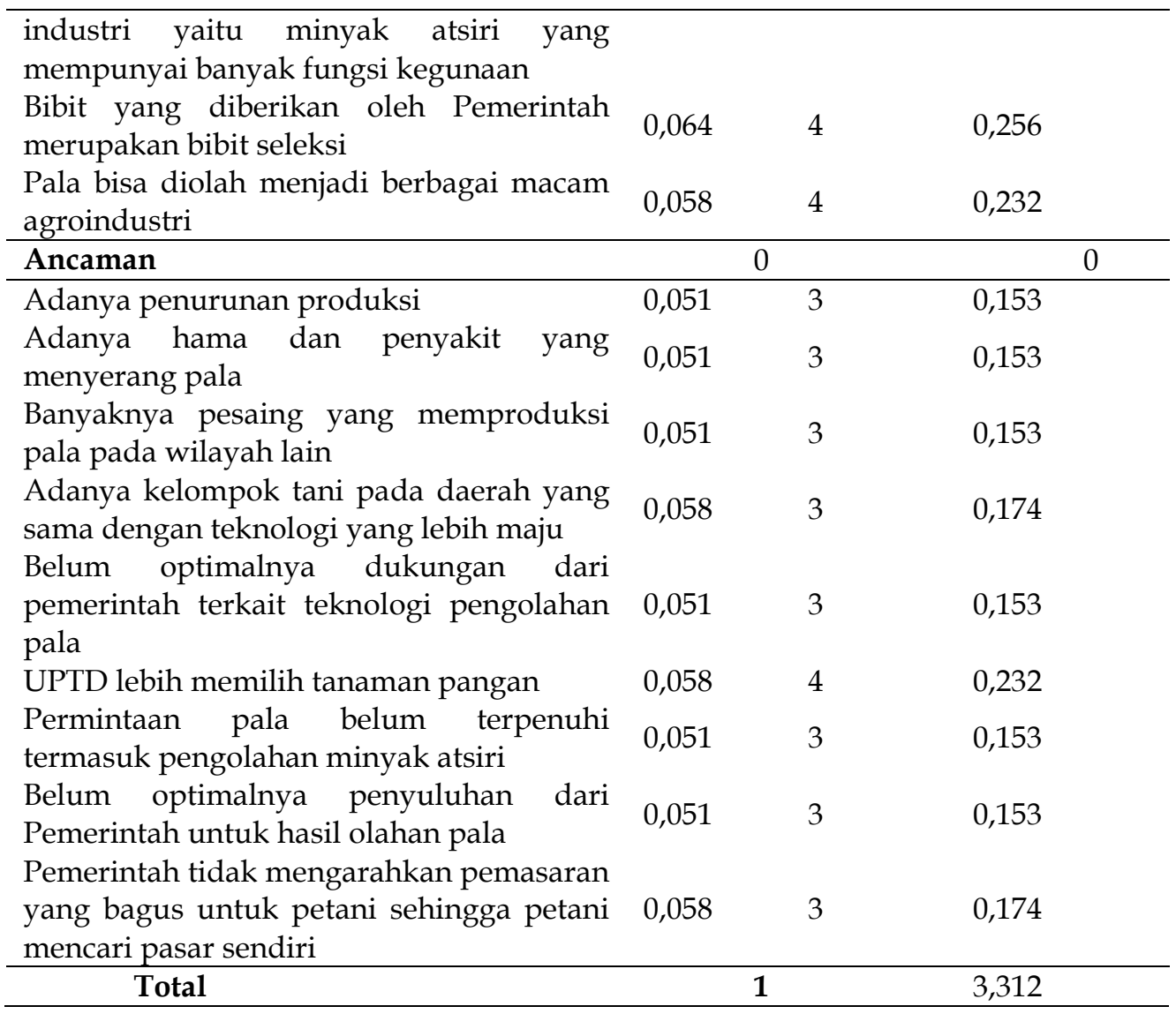

\section{Strategi ST}

Strategi ini menggunakan kekuatan perusahaan untuk menghindari atau mengurangi pengaruh dari ancaman eksternal. Strategi ST yang dapat diterapkan adalah

Memberikan Pelatihan yang baik kepada petani baik dari segi pemasaran, budidaya dan pengembangan tekonologi agar pala mampu bersaing. Pelatihan yang diberikan oleh Pemerintah dapat mengatasi ancaman yang ada pada petani dengan memanfaatkan kekuatan petani yaitu tenaga kerja

Keikutsertaan UPTD dalam hal pembudidayan dan HPT buah pala.

\section{Strategi WT}

Strategi ini bertujuan untuk mengurangi atau meminimalkan kelemahan internal untuk menghindari ancaman eksternal. Strategi WT yang merupakan strategi defensif untuk bertahan atau melakukan penciutan. Dari ancaman dan kelemahan yang dimiliki, maka strategi yang bisa di pakai adalah:

Mengoptimalkan sumberdaya dan pemasaran yang dimiliki 
Sumberdaya seperti tanah yang subur dan hasil produk pala yang termasuk terbaik dapat membuat Kelompok Tani di Tanjung Sani mengoptimalkan sumberdaya yang ada untuk bertahan dari ancaman yang ada.

Melakukan hubungan kerjasama antar kelompok tani yang mempunyai teknologi lebih maju dengan Kelompok Tani di Tanjung Sani.

\section{SIMPULAN DAN SARAN}

\section{Kesimpulan} pulkan :

Berdasarkan hasil analisa data yang telah dilakukan maka dapat disim-

Strategi yang dapat dilakukan untuk pengembangan pala di Kecamatan Tanjung Raya Kabupaten Agam adalah : Membangun hubungan kerjasama dengan pihak pemerintah dan swasta, peningkatan perbaikan teknologi nilai tambah dan pendapatan petani melalui agroindustri pala, pemerintah dengan pihak yang terkait melakukan promosi komoditas pala baik di dalam maupun luar negeri, mengikuti pelatihan yang diadakan oleh pihak pemerintah terkait pengolahan hasil produk pala, membentuk rumah HPT untuk dapat mengatasi hama dan penyakit yang menyerang, memberikan pelatihan yang baik kepada petani baik dari segi pemasaran, budidaya dan pengembangan teknologi, keikutsertaan UPTD dalam hal pembudidayaan dan HPT buah pala, mengoptimalkan sumber daya dan pemasaran yang dimiliki dan membangun kerjasama antar kelompok tani yang mempunyai teknologi lebih maju.

\section{Saran}

Berdasarkan hasil penelitian yang telah dilakukan, maka dapat diberikan beberapa saran sebagai berikut:

1. Untuk meningkatkan nilai tambah dari pala maka dapat dilakukan dengan memberikan pelatihan kepada petani dalam hal budidaya, pemasaran dan pasca panen.

2. Pemerintah diharapkan mapu memberikan pelatihan ataupun membentuk rumah HPT dalam mengatasi hama penyakit pada pala yaitu busuk akar.

\section{DAFTAR PUSTAKA}

Asmara, Rosihan. 2004. Sumbangan ke Metan-presiden-editan2. Universitas Brawijaya. Malang. 
BPS. 2013. Tanjung Raya Dalam Angka. Kabupaten Agam.

Hidayati, Reny. 2011. Perbandingan Pendapatan dan Keuntungan Petani Pala Antara Penjualan Dalam Bentuk Basah dan Kering di Kecamatan Tanjung Raya Kabupaten Agam. Skripsi Fakultas Pertanian Unand. Padang.

Nazir, Moh. 2005. Metode Penelitian. PT Ghalia Indonesia. Bogor Selatan. Simatupang, Jones. 2005. Analisa Ekonomi Usahatani dan Tingkat Efisiensi Pencurahan Tenaga Kerja pada Usahatani Melon. Fakultas Pertanian. Universitas Methodist Indonesia. Medan. 